European Federation of Societies for Ultrasound in Medicine and Biology

\title{
EFSUMB Schools, UEG virtual Ultrasound Learning Area and EUROSON Congress
}

\section{Euroson Schools}

The CEUS School in Munich was held as a highly successful hybrid course and the recordings can be viewed on the EFSUMB website https://www.efsumb.org/blog/post-graduate-web-courses The course was organized by Prof Dirk Clevert and Prof Hans-Peter Weskott with recorded lectures from around the globe.
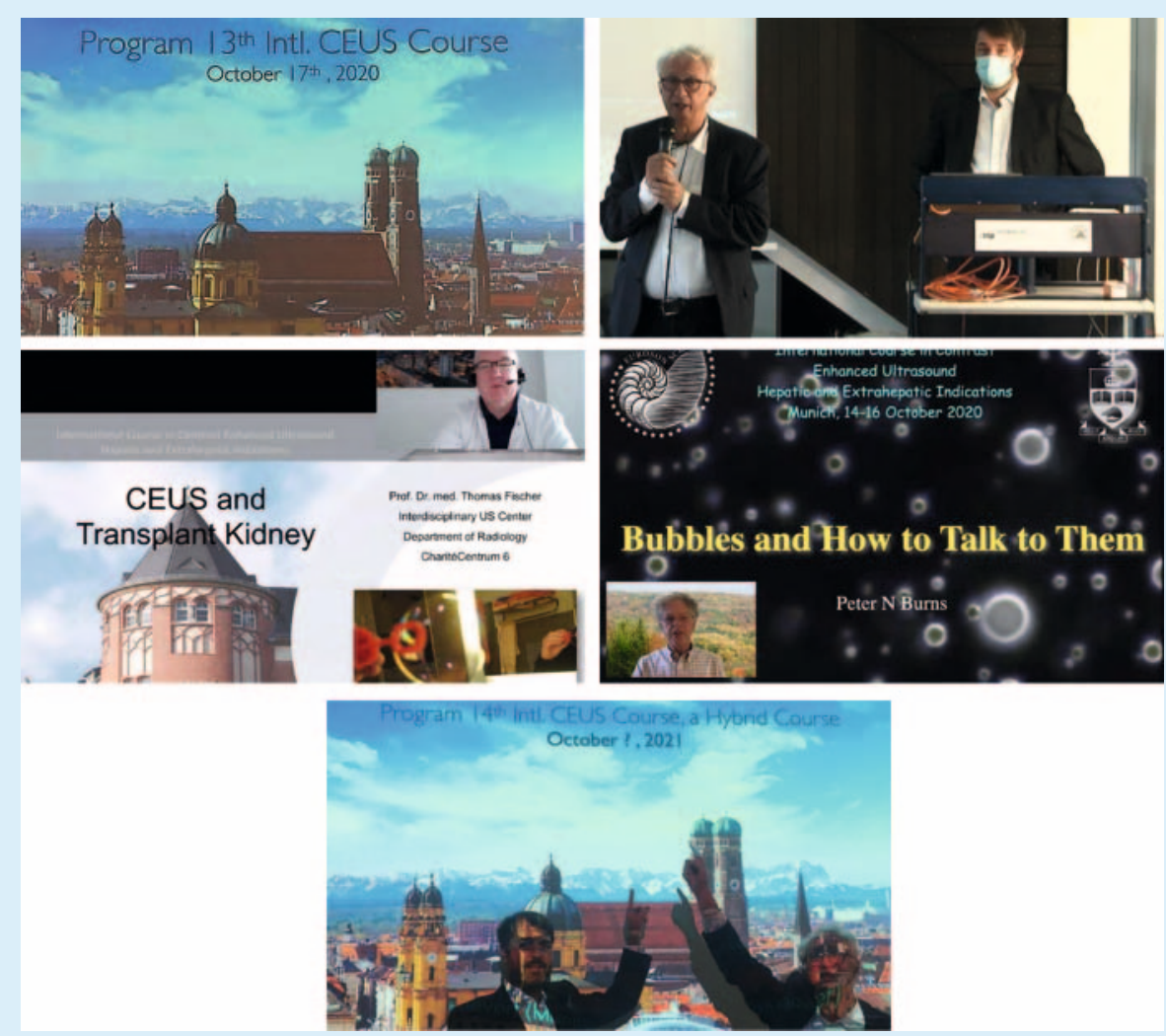

A CEUS course will take place again in 2021 in Munich as a hybrid course with the date to be decided soon and announced on www.efsumb.org.
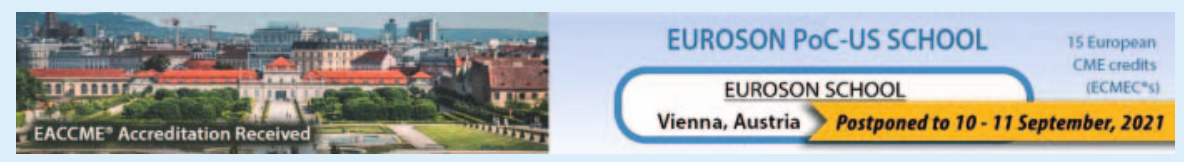

The PoCUS School in Vienna has been postponed to 10-11 September 2021.

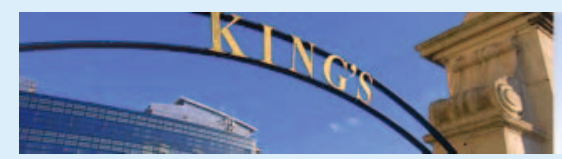

\section{London CEUS Ultrasound Course}

EUROSON SCHOOL

London, UK 21 - 22 June 2021

Confirmed dates for London CEUS Course. 


\section{Ultrasound at UEG Week Virtual 2020}

For more then 17 years Ultrasound is present at the largest European Meeting of the Gastroenterologists - The United European Gastroenterology Week (UEGW), a meeting that gathers around 14000 participants interested in everything about Gastroenterology and Hepatology. It is present in a special designated area, the Ultrasound Learning Area, where faculty from different counties teach anybody that it is interested, in the basic and the advanced features of ultrasonography for the gastroenterologists. The Ultrasound Learning Area (ULA) offers basic and advanced postgraduate courses on ultrasonography, individual hands-on training, and special lectures in abdominal ultrasonography. The program is designed for both young and senior gastroenterolo- gists and promotes the role of a major diagnostic and interventional tool in gastroenterology: clinical ultrasonography in the hands of gastroenterologists!

This year the UEGW was marked by novelty, being for the first time, due to the SARS COV2 pandemic, a completely virtual conference. So also, the Ultrasound Learning Area, that runs in courtesy of EFSUMB and BICUS, and this year with the help of GE Healthcare as sponsor, had to adjust to the new situation. The program was concentrated in one day and offered, as usual, lectures on basic and advanced ultrasound, interactive case discussions, and most importantly, live demonstrations of different clinical cases.

The faculty of the ULA, Prof. Dieter Nürnberg, Neuruppin, Germany, Prof. Ioan Sporea,

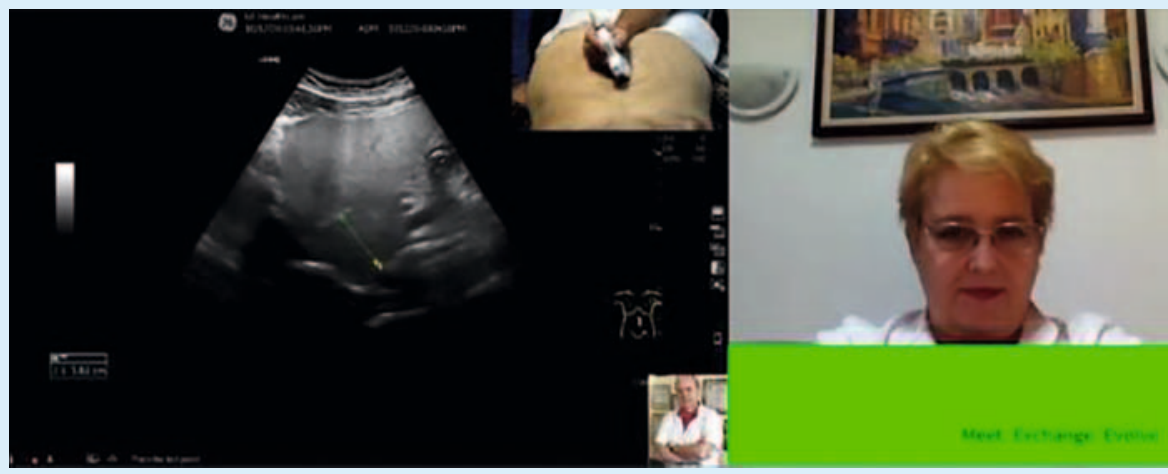

The virtual format of the meeting was challenging enough, being completely new. The live sessions brought an element of challenge and tension, but also the satisfaction of being able to directly demonstrate the usefulness of this important technique for the clinical practice of the gastroenterologists. We were able to show the participants cases of conventional ultrasound, contrast enhanced ultrasound, ultrasound
Timişoara, Romania, Prof. Alina Popescu, Timişoara, Romania, Dr. Christian Jenssen, Strausberg-Wriezen, Germany, Dr. Kim Nylund, Bergen, Norway, Prof. Roxana Şirli, Timişoara, Romania and Dr. Thomas Müller, Wiesbaden, Germany, focused in the lectures on basic knowledge in ultrasound, like how to scan the liver, how to examine the pancreas, etc., but also on the role of ultrasound in diagnosing different abdominal pathologies. The lectures were followed by live panel discussion of the faculty on cases of bowel ultrasound and then by two live demonstration sessions, where several pathological cases were presented alternately from Timişoara, Romania by Prof. Ioan Sporea and Prof. Alina Popescu with the help of Dr. Felix Bende, and from Neuruppin, Germany by Prof. Dieter Nürnberg and Dr. Christian Jenssen, with the help of the medical students Eva Hamm and David Boten. based elastography and steatosis quantification. The interest of the participants was proved by the attendance and by the interaction with the faculty through questions. 


\section{EUROSON 2021/WFUMB 2021}

For Timişoara, Ultrasound will bring another challenge next year. Between May 26-29, 2021 Timișoara will be The World Capital of Ultrasound, with three major ultrasound events in conjunction: The 18th World Federation for Medicine and Biology Congress, the $33^{\text {rd }}$ Congress of EFSUMB - EUROSON
2021 and the $24^{\text {th }}$ National Conference of The Romanian Society of Ultrasound in Medicine and Biology. The congress will maintain the tradition of a balanced program, including a range of postgraduate courses focused on different fields of ultrasound and will also bring the newest information in diagnostic and interventional ultrasonography, covering the usual broad range of topics. As your hosts we will try to surprise you with a rich and interesting scientific program but also with the Romanian hospitality, and offer you the experience of our nice city, Timișoara.

So this is also an invitation for all that are interested in Ultrasound to join us in Timișoara in 2021!

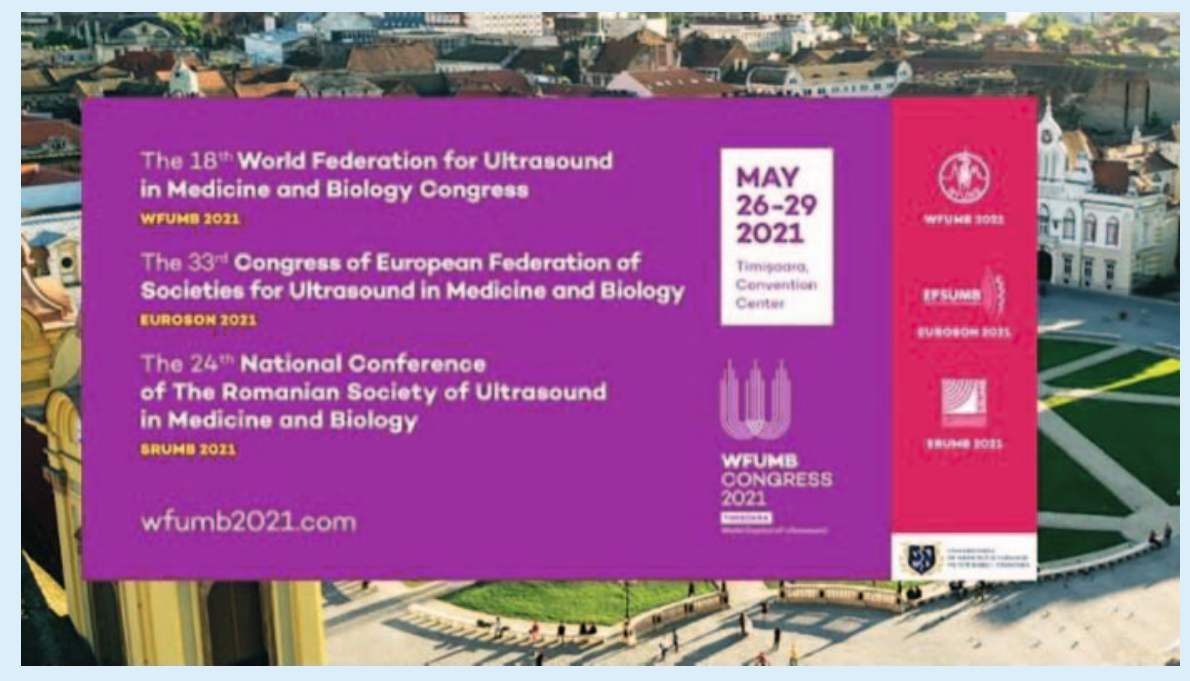

